\title{
IbM Usaha Miniatur Kapal Berbasis Industri Kreatif Di Bangkalan, Madura
}

\author{
Chairul Anam \\ Fakultas Ekonomi dan Bisnis, Universitas Trunojoyo Madura
}

\begin{abstract}
Abstrak
Kegiatan Iptek Bagi Masyarakat (IbM) ini berlangsung di lokasi mitra, Jl.Dumarah RT 1, RW 9 (Bedak Barat) Desa Banyuajuh, Kamal, Madura. Tujuan dari kegiatan ini untuk memberikan pendampingan dari manajemen usaha terutama dari aspek keuangan, aspek pemasaran, aspek produksi dan aspek sumberdaya manusia.Ada 2 unit usaha industri kreatif yang dilakukan pendampingan yaitu UMKM Cakraningrat Ship Model dan UKM Madura Miniatur, kedua UMKM bergerak dalam bidang usaha miniatur kapal. UKM ini mengalami kendala dalam mengembangkan kegiatan usahanya dari sisi pemasaran,produksi,keuangan dan sumberdaya manusia. Solusi yang ditawarkan dari sisi keuangan,perlu ada pemisahan administrasi antara keuangan keluarga dan keuangan bisnis, dari sisi produksi perlu ada penambahan peralatan,dari sisi sumberdaya manusia perlu menambah kuantitas dank kualitas tenaga kerja,dari sisi pemasaran perlu banyak mengikuti pameran dan memperluas promosi. Metode pelaksanaan kegiatan yang dilakukan dengan pendidikan, pelatihan,pendampingan, penyuluhan dan konsultasi, manajemen usaha dan adopsi teknologi yang tepat untuk meningkatkan kuantitas,kualitas dan profitabilitas produk. Untuk keberhasilan kegiatan ini,maka diperlukanperan sertamitrasecara pro aktif dalammenentukan pendekatan solusi yang digunakan,untuk mendapat pendidikan,pelatihan,dan pendampingan serta aktif berkonsultasi tentang berbagai hal yang dihadapi perusahaannya, dan dalam menentukan rencana solusi alternatif, maka keputusan akan didiskusikan bersama.
\end{abstract}

Kata kunci: UMKM, industri kreatif, miniatur kapal, produksi, pemasaran, sumberdaya manusia, dan administrasi keuangan.

\section{PENDAHULUAN}

Kabupaten Bangkalan terletak di ujung barat pulau madura dengan luas wilayah mencapai $1.260,14 \mathrm{Km} 2$,dengan batas wilayah sebelah utara Laut Jawa,sebelah timur berbatasan dengan Kabupaten Sampang, sebelah barat berbatasan dengan selat Madura, sebelah selatan berbatasan dengan Selat Madura. Secara geografis letak Kabupaten Bangkalan pada titik koordinat 1120 40' 06" - 1130 08' 04" Bujur Timur dengan 60 51' 39" - 7o 11'39" Lintang Selatan.

Dengan letak geografis seperti tersebut diatas posisi Kabupaten Bangkalan sangat strategis sebagai pintu gerbang lalu lintas barang dan penumpang dari dan ke Madura.Perkembangan usaha kecil dan menengah dari waktu ke waktu menunjukkan perkembangan yang pesat. Banyak sekali produk unggulan yang dihasilkan oleh Kabupaten Bangkalan yang tersebar di beberapa kecamatan, produk-produk unggulan yang dihasilkan antara lain : batik tulis, sangkar burung,pande besi, jamu tradisional,ukiran kayu,genteng,kerajinan batu-batuan dsb.

Mitra untuk kegiatan IbM ini ada 2 yaitu yang pertama UKM Mitra I adalah Gallery Cakraningrat Ship Model yang dikelola oleh Bapak Abdul Halim yang didirikan tahun 1994,sebuah Industri kecil yang menjadi mitra dalam kegiatan Ipteks ini, UKM ini menghasilkan industri kreatif yang berupa kerajinan miniatur kapal yang berada di desa Banyuajuh Jl. Paseraman RT 03 RW 03 Kecamatan Kamal Kabupaten Bangkalan Madura dengan alamat email : csm.halim@yahoo.co.id dan Nomor telpon seluler (HP) 081330439191 dan 085732659669 dan UKM ini telah banyak berpengalaman membuat berbagai miniatur dengan berbagai macam jenis dengan skala tertentu dan diakui oleh perusahaan-perusahaan pelayaran dan galangan kapal ternama antara lain: PT. PAL Indonesia, PT. Dharma Lautan Utama (DLU), PT. Dumas, PT. Damen, PT. Landasindo Sahu Baruna Jaya (PT Humpuss Trading), PT. Adi Luhung Sarana Segara, PT. Jasa Marina Indah Semarang, PT. 


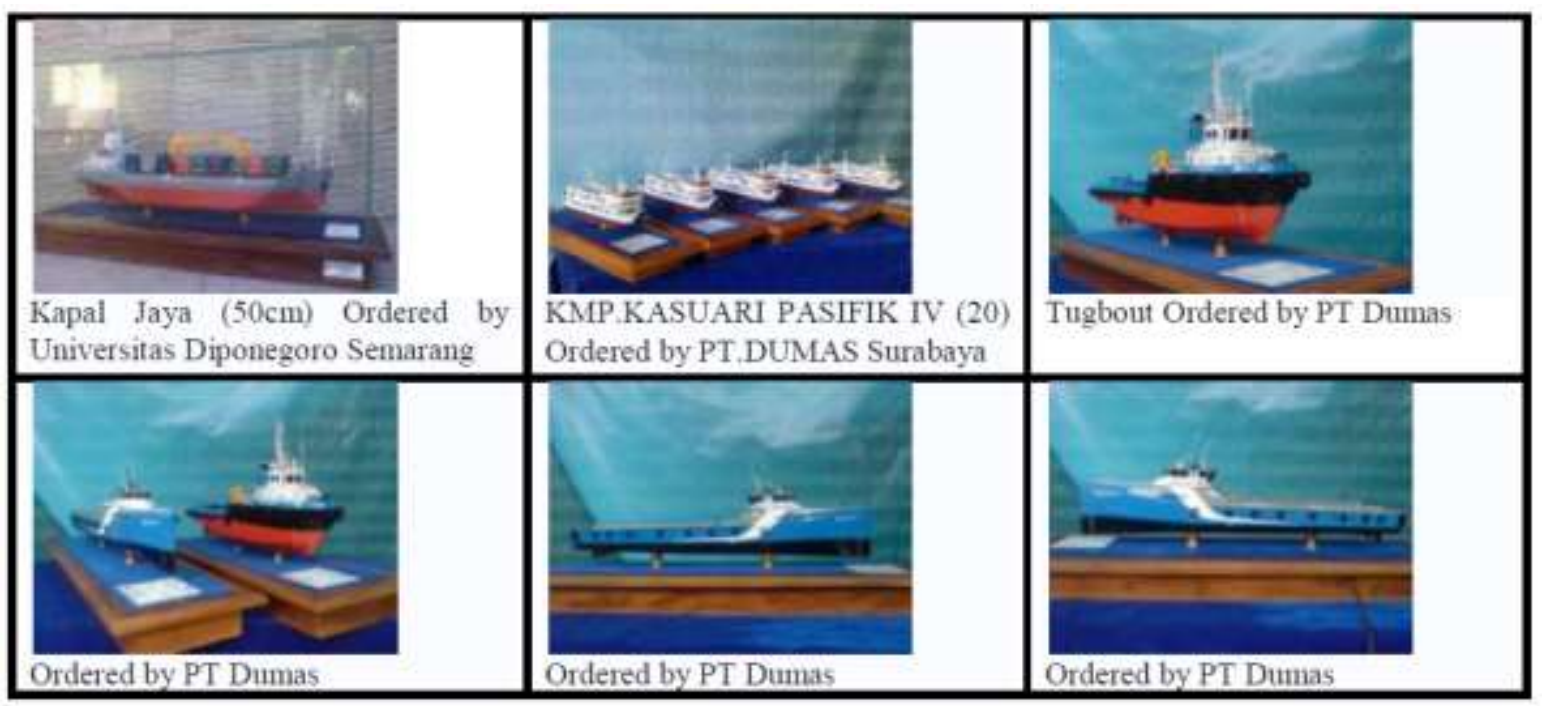

Gambar 1. Produk yang telah dihasilkan oleh Gallery Cakraningrat Ship Model

Karya Jaya Samudera Surabaya dengan harga bervariasi antara Rp 1.500.000,- sampai Rp 7.500.000,- tergantung besar kecilnya maket dan tingkat kesulitan nya. Jenis miniatur kapal yang telah dihasilkan antara lain : kapal tanker, kapal penumpang, kapal perang, kapal selam, kapal fery, kapal LPG/LNG dsb. Produk yang telah dihasilkan oleh Gallery Cakraningrat Ship Model seperti pada gambar dibawah ini :

Kedua,UMKM Mitra II adalah Madura Miniatur yang dikelola oleh Bapak Moh Taufikadalah sebuah industri kecil yang menjadi mitra dalam kegiatan Iptek bagi masyarakat (IbM) ini telah berpengalaman sejak tahun 1997 yang memproduksi maket/miniatur kapal yang berlokasi di Perumahan Graha Chandraland Blok F1,Jln. Martadinata Bangkalan, dengan nomor ponsel 081913563076.UKM ini merupakan spesialis miniatur kapal /ship model / maket kapal yang dibuat dengan skala yang tepat dan akurat yang dapat digunakan dalam serah terima kapal secara simbolis, Mitra kerja UKM ini banyak dari perusahaan pelayaran, galangan kapal, SMK Pelayaran dan Lembaga pendidikan tinggi perkapalan. Adapun nama-nama perusahaan tersebut antara lain : PT. PAL Indonesia, PT. Dharma Lautan Utama (DLU), PT. Adi Luhung Sarana Segara, PT. Karya Jaya Samudera Surabaya, PT. Landasindo Surabaya. Produk yang telah dihasilkan antara lain seperti pada gambar ini

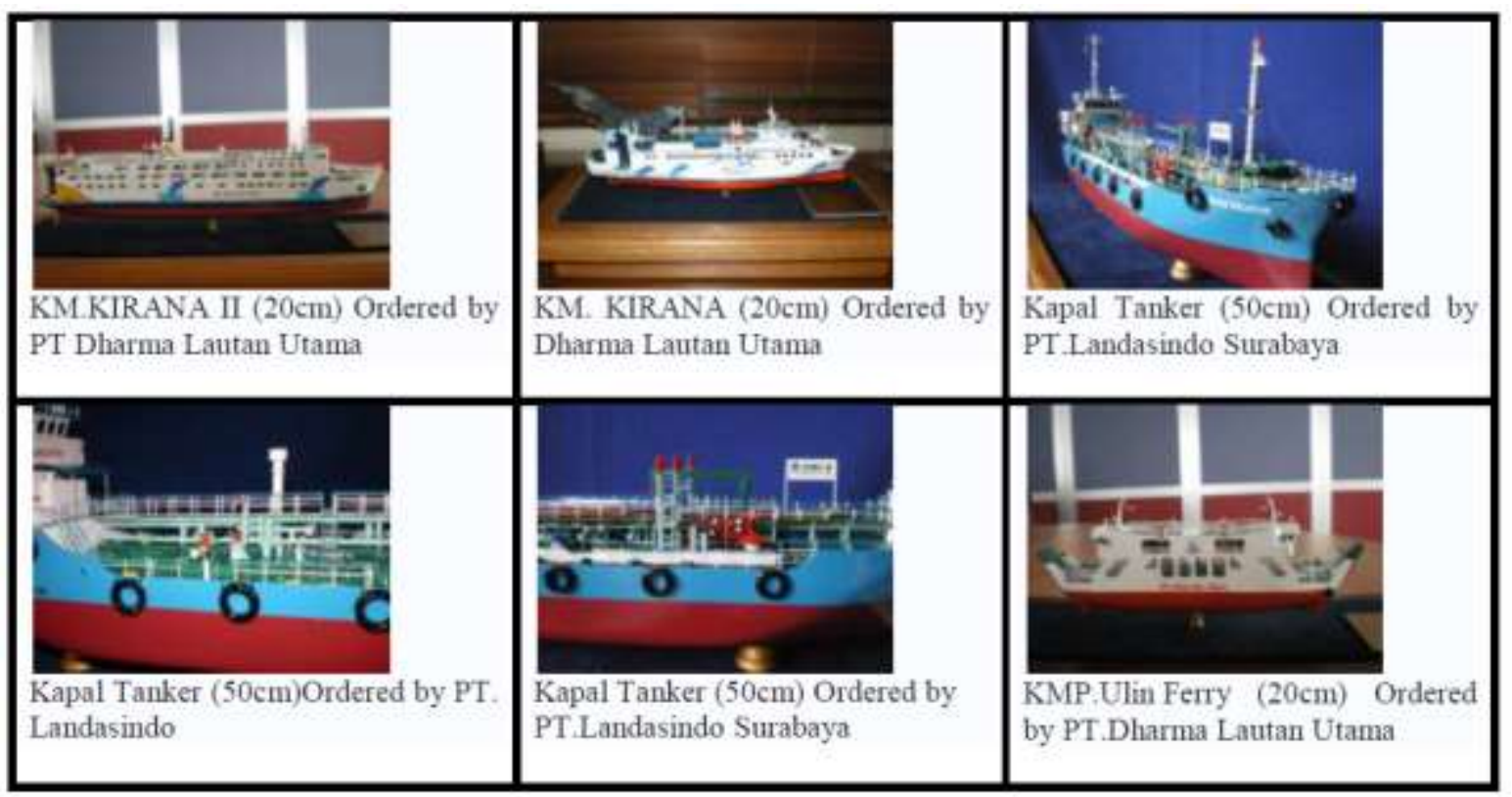

Gambar 2. Produk Mitra kerja UKM 
Permasalahan pada Mitra 1 Cakraningrat ship model, Berdasarkan pada analisis situasi, dan berdasarkan hasil diskusi dengan mitra maka dapat diidentifikasi beberapa kendala permasalahan yang dihadapi oleh usaha miniatur kapal apabila ditinjau dari aspek manajemen usaha secara ringkas adalah sebagai berikut : 1) Aspek produksi : kurangnya peralatan produksi untuk membuat miniatur kapal dengan skala yang akurat,belum dibuat secara knockdown, belum bisa menggunakan remote control, sehingga belum bisa dikendalikan dari jarak jauh, 2) Kegiatan promosi yang dilakukan sudah menggunakan tehnologi informasi dengan menggunakan situs oline, namun perlu dilengkapi dengan alternative kegiatan promosi yang lain misalnya : kegiatan-kegiatan pameran, dan jemput bola langsung ke perusahaan mitra usaha yang memerlukan antara lain : galangan kapal, SMK Kejuruan, Fakultas tehnik perkapalan dsb. 3) Aspek Sumber Daya Manusia/Tenaga Kerja :Tingkat ketrampilan tenaga kerja sangat terbatas, untuk itu perlu memperbaiki metode perekrutan tenaga kerja yang lebih selektif dan melalui proses magang .4) Aspek Keuangan : Administrasi keuangan masih sederhana belum ada pemisahan antara pengelolaan keuangan pribadi dan usaha/bisnis, pencatatan keuangan masih belum memenuhi standar akuntansi yang benar.

Permasalahan Mitra 2 Madura Miniatur, 1) Aspek produksi : pembelian Bahan baku secara bertahap sesuai dengan order, belum melakukan diversifikasi produk,kurangnya peralatan produksi baik yang manual maupun mekanis.2)Aspek Pemasaran : Penentuan harga di tentukan berdasarkan kesepakatan dengan pemesan dengan metode perhitungan konvensional, Perluasan jaringan pemasaran baik lokal, nasional, dan ekspor dengan membuat katalog produk, mengadakan pameran pada event-event khusus, 2) Aspek Sumber Daya Manusia/Tenaga Kerja : Produktifitas tenaga kerja masih rendah.3) Aspek Keuangan : Belum ada pemisahan secara jelas antara kekayaan pemilik dan kekayaan perusahaan, Masih belum punya perencanaan usaha ke depan/jangka panjang.

Tujuan dari kegiatan ini adalah, 1) Mempunyai ijin usaha atas hasil produksinya dari instansi terkait.2) Kualitas produk miniature kapal semakin meningkat baik dari sisi kemiripan dengan produk asli dan akurasi ukuran dan skalanya, dengan menggunakan peralatan yang lebih modern dan memanfaatkan tehnologi tepat guna yang bersifat elektrik dan mekanis. 3) Mampu membuat administrasi pembukuan keuangan secara sederhana yang sesuai dengan standar akuntansi yang benar,4) Kuantitas penjualan yang semakin meningkat dengan melakukan promosi yang lebih agresif dan strategi pemasaran yang lebih intensif.5) Mitra usaha mampu membuat perencanaan usaha untuk memperkirakan peluang pasar, memperediksi besarnya permintaan, kebutuhan modal dan sebagainya.6) Ketrampilan dan produktifitas tenaga kerja semakin meningkat.

\section{HASIL DAN PEMBAHASAN}

\section{- Persiapan pendahuluan.}

Sebelum melakukan kegiatan IbM ini persiapan yang dilakukan antara lain, mengurus surat ijin kegiatan dari Pemerintah Kabupaten Bangkalan $\mathrm{Cq}$ Badan Kesatuan Bangsa dan Politik. Kegiatan selanjutnya adalah melakukan perekrutan mahasiswa untuk melakukan pendampingan sebanyak 5 orang mahasiswa,sebelum melakukan pendampingan para mahasiswa diberikan pembekalan singkat mengenai tugas yang akan dilaksanakan kepada mitra UMKM,agar para mahasiswa dapat melaksanakan tugasnya dengan baik.

\section{- Kegiatan pembekalan kepada Mitra}

Sebelum melakukan pendampingan, Mitra diberikan pembekalan materi oleh nara sumber yang berkompeten yaitu dosen dari Fakultas Tehnik dan Fakultas Ekonomi dan Bisnis Universitas Trunojoyo. Nara sumber yang berasal dari Fakultas Tehnik mengkritisi website yang dimiliki oleh mitra dan sekaligus memberikan solusinya sedangkan nara sumber yang berasal dari Fakultas Ekonomi dan Bisnis memberikan materi mengenai manajemen usaha yang meliputi : manajemen pemasaran, manajemen sumberdaya manusia, manajemen produksi dan manajemen keuangan

\section{- Pendampingan kepada Mitra}

Pendampingan kepada Mitra dilakukan setelah Mitra menerima pembekalan dari nara sumber,sehingga mitra dapat melaksanakan materi pembekalan yang telah dilakukan oleh nara sumber. Pendampingan, bimbingan dan monitoring secara kontinyu dilakukan oleh para 
mahasiswa.

\section{- Bimbingan dan Konsultasi}

Keberhasilan kegiatan program IbM ini diperlukan peran aktif dari mitra untuk berkonsultasi dan menanyakan berbagai hal yang berkaitan dengan bisnis usahanya,mulai dari aspek pemasaran, aspek produksi, aspek sumberdaya manusia dan aspek administrasi keuangan.

\section{ANALISIS S W O T}

Untuk menentukan strategi yang bisa dilakukan oleh pelaku bisnis industri kreatif miniatur kapal terutama UKM miniatur kapal 'Cakraningrat ship model' dan 'Madura Miniatur' analisis SWOT sangat membantu karena instrumen perencanaaan strategis ini menggunakan kerangka kerja kekuatan dan kelemahan dan kesempatan ekternal dan ancaman, instrumen ini memberikan cara sederhana untuk memperkirakan cara terbaik untuk melaksanakan sebuah strategi. Instrumen ini menolong para perencana apa yang bisa dicapai, dan hal-hal apa saja yang perlu diperhatikan oleh mereka.

\section{- Tujuan Analisis}

Untuk memberikan gambaran hasil analisis keunggulan, kelemahan, peluang dan ancaman perusahaan secara menyeluruh yang digunakan sebagai dasar atau landasan penyusunan objective dan strategi perusahaan dalam corporate planning.

Kerangka SWOT - sebuah matrix dua kali dua - sebaiknya dikerjakan dalam suatu kelompok yang terdiri dari anggota kunci tim atau organisasi. Pertama, penting untuk diketahui dengan jelas tentang apa tujuan perubahan kunci, dan terhadap tim atau organisasi apa analisis SWOT akan dilakukan. Setelah pertanyaanpertanyaan ini dijelaskan dan disepakati, mulailah dengan brainstorming gagasan, dan kemudian setelah itu dipertajam dan diperjelas dalam diskusi.

Analisis SWOT merupakan salah satu metode untuk menggambarkan kondisi dan mengevaluasi suatu masalah, proyek atau konsep bisnis yang berdasarkan faktor internal (dalam) dan faktor eksternal (luar) yaitu Strengths, Weakness, Opportunities dan Threats. Metode ini paling sering digunakan dalam metode evaluasi bisnis untuk mencari strategi yang akan dilakukan.
Analisis SWOT hanya menggambarkan situasi yang terjadi bukan sebagai pemecah masalah. Secara rinci kondisi internal dan eksternal UKM Cakraningrat Ship Model' dan 'Madura Miniatur' seperti dibawah ini.

\section{- Kekuatan}

1. Berdiri sejak th 1994

2. Tingkat upah untuk tenaga kerja relatif murah.

3. Modal awal pendirian usaha rendah

4. Barang diproduksi berdasarkan pesanan, sehingga tidak ada barang sisa.

5. Bahan baku dan material mudah diperoleh

6. Produk yang dihasilkan bisa dibuat dengan Peralatan produksi sederhana

7. Sudah memiliki akte pendirian

\section{- Kelemahan}

1. Kualitas skill pekerja berdasarkan bakat.

2. Jumlah pekerja terbatas dan sulit didapat

3. Pendidikan pekerja terbatas

4. Peralatan terbatas

5. Manajemen usaha pemilik masih sederhana.

6. Pengelolaan keuangan masih dipisahkan antara keuangan usaha dan keuangan keluarga.

7. Modal usaha yang dimilikiterbatas.

8. Pangsa pasar tetap masih terbatas.

\section{- Peluang}

1. Pangsa pasar luas.

2. Tingkat permintaan produktinggi.

3. Produk yang dihasilkan merupakan salahsatu produk yang unik dan khusus.

\section{- Ancaman}

1. Harga bahan material cenderung naik.

2. Munculnya pesaing baru untuk produk yang sejenis. 
Tabel 1. Analisis Matriks SWOT UKM Miniatur Kapal,di Bangkalan 'Cakraningrat Ship Model' dan 'Madura Miniatur'

\begin{tabular}{|c|c|c|}
\hline \multirow{2}{*}{ 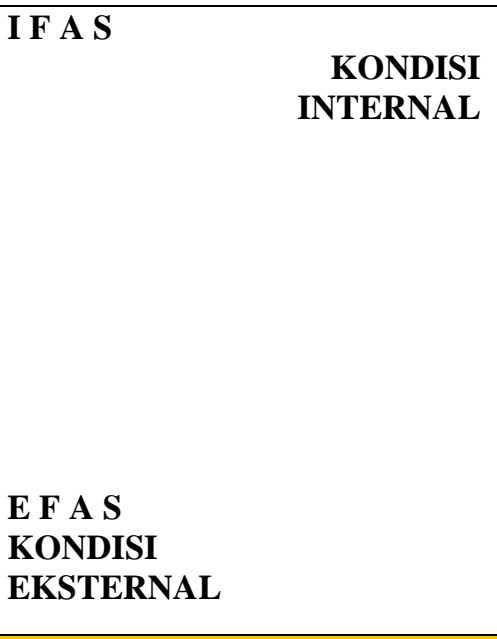 } & $\begin{array}{l}\text { STRENGH (S) } \\
\text { KEKUATAN }\end{array}$ & $\begin{array}{l}\text { WEAKNESS (W) } \\
\text { KELEMAHAN }\end{array}$ \\
\hline & $\begin{array}{l}\text { 1) } \begin{array}{l}\text { Berdiri sejak th } 1994 \\
\text { 2) }\end{array} \\
\text { Tingkat upah untuk tenaga kerja } \\
\text { relatif murah. } \\
\text { 3) } \begin{array}{l}\text { Modal awal pendirian usaha } \\
\text { rendah }\end{array} \\
\text { 4) } \begin{array}{l}\text { Barang diproduksi berdasarkan } \\
\text { pesanan, sehingga tidak ada }\end{array} \\
\text { barang sisa. } \\
\text { 5) } \\
\text { Bahan baku dan material mudah } \\
\text { diperoleh } \\
\text { 6) Produk yang dihasilkan bisa } \\
\text { dibuat dengan Peralatan produksi } \\
\text { sederhana } \\
\text { 7) Sudah memiliki akte pendirian }\end{array}$ & $\begin{array}{l}\text { 1) } \begin{array}{l}\text { Kualitas skill pekerja } \\
\text { berdasarkan bakat. }\end{array} \\
\text { 2) Jumlah pekerja terbatas dan sulit } \\
\text { didapat } \\
\text { 3) Pendidikan pekerja terbatas } \\
\text { 4) Peralatan terbatas } \\
\text { 5) Manajemen usaha pemilik masih } \\
\text { sederhana. } \\
\text { 6) Pengelolaan keuangan masih } \\
\text { dipisahkan antara keuangan } \\
\text { usaha dan keuangan keluarga. } \\
\text { 7) Modal usaha yang } \\
\text { dimilikiterbatas. } \\
\text { 8) Pangsa pasar tetap masih } \\
\text { terbatas. }\end{array}$ \\
\hline $\begin{array}{l}\text { OPPORTUNITY (O) } \\
\text { PELUANG }\end{array}$ & $\begin{array}{c}\text { STRATEGI } \\
\text { S - O }\end{array}$ & $\begin{array}{c}\text { STRATEGI } \\
\text { W - O }\end{array}$ \\
\hline $\begin{array}{l}\text { 1) Pangsa pasar luas. } \\
\text { 2) pingkat permintaan } \\
\text { produktinggi. } \\
\text { 3) Produk yang dihasilkan } \\
\text { merupakan salahsatu produk } \\
\text { yang unik dan khusus. }\end{array}$ & 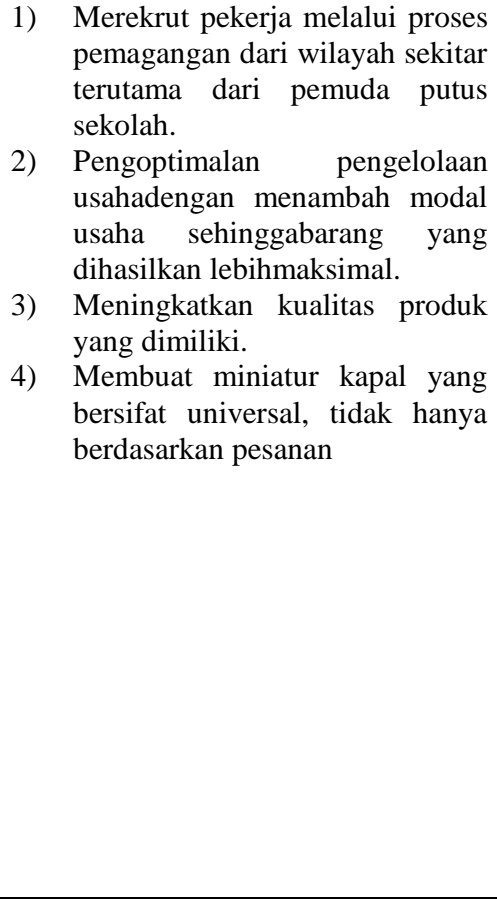 & 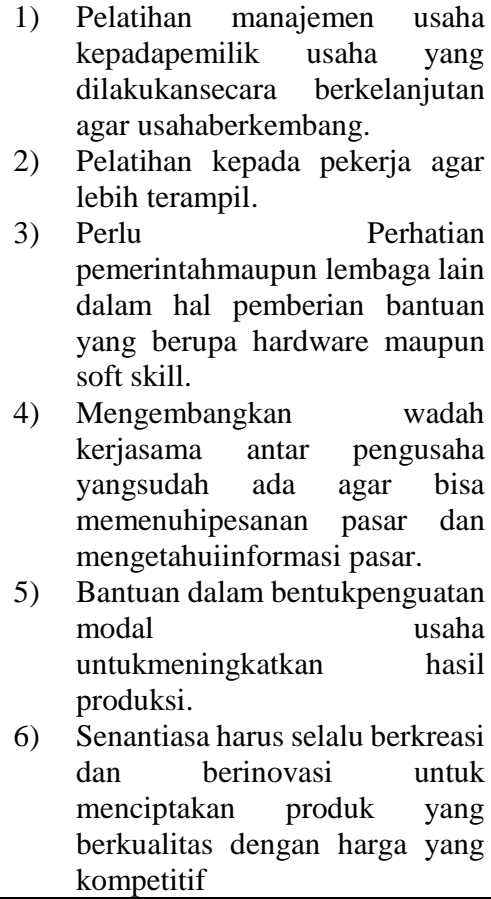 \\
\hline $\begin{array}{l}\text { TREATH }(\mathrm{T}) \\
\text { ANCAMAN }\end{array}$ & $\begin{array}{c}\text { STRATEGI } \\
\text { S - T }\end{array}$ & $\begin{array}{c}\text { STRATEGI } \\
\text { W - T }\end{array}$ \\
\hline $\begin{array}{l}\text { Harga bahan material } \\
\text { cenderung naik. } \\
\text { 2) } \\
\text { Munculnya pesaing baru untuk } \\
\text { produk yang sejenis. } \\
\text { Muncul banyak produk sejenis } \\
\text { dengan inovasi baru. }\end{array}$ & 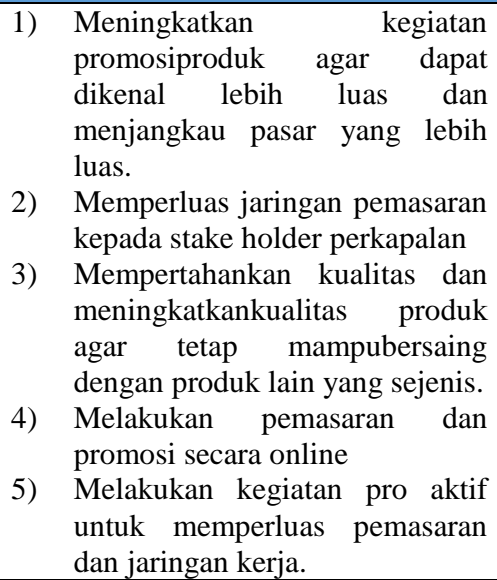 & 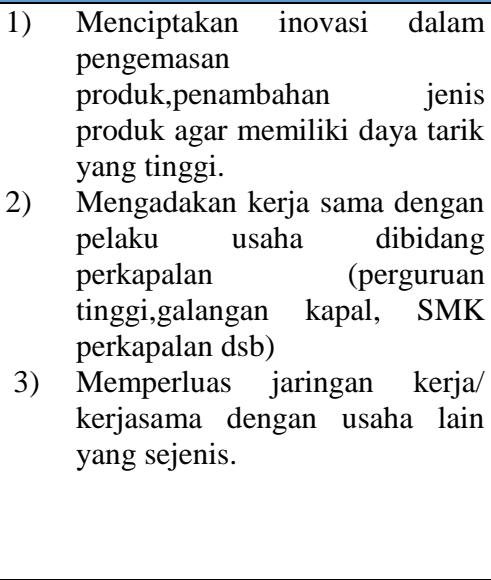 \\
\hline
\end{tabular}


Adapun strategi yang bisa dilakukan berdasarkan kekuatan dan peluang (Strength Opportunity) barang yang dihasilkan lebihmaksimal.

1. Meningkatkan kualitas produk yang dimiliki.

2. Membuat miniatur kapal yang bersifat universal, tidak hanya berdasarkan pesanan

\section{- Strategi usaha berdasarkan W - O}

1. Pelatihan manajemen usaha kepadapemilik usaha yang dilakukansecara berkelanjutan agar usahaberkembang.

2. Pelatihan kepada pekerja agar lebih terampil.

3. Perlu Perhatian pemerintah maupunlembaga lain dalam halpemberian bantuan yang berupa hardware maupun soft skill.

4. Mengembangkan wadah kerjasama antar pengusaha yangsudah ada agar bisa memenuhipesanan pasar dan mengetahuiinformasi pasar.

5. Bantuan dalam bentukpenguatan modal usaha untukmeningkatkan hasil produksi.

6. Senantiasa harus selalu berkreasi dan berinovasi untuk menciptakan produk yang berkualitas dengan harga yang kompetitif

\section{- Strategi usaha berdasarkan S - T}

1. Meningkatkan kegiatan promosiproduk agar dapat dikenal lebih luas dan menjangkau pasar yang lebihluas.

2. Memperluas jaringan pemasaran kepada stake holder perkapalan

3. Mempertahankan kualitas dan meningkatkankualitas produk agar tetap mampubersaing dengan produk lain yang sejenis.

4. Melakukan pemasaran dan promosi secara online

5. Melakukan kegiatan pro aktif untuk memperluas pemasaran dan jaringan kerja.

\section{- Strategi usaha berdarakan W - T}

1. Menciptakan inovasi dalam pengemasan produk,penambahan jenis produk agar memiliki daya tarik yang tinggi.

2. Mengadakan kerja sama dengan pelaku usaha dibidang perkapalan (perguruan tinggi,galangan kapal, SMK perkapalan dsb)

3. Memperluas jaringan kerja/ kerjasama dengan usaha lain yang sejenis.

Adapun kerangka matriks UKM Miniatur kapal sebagai mitra IbM selengkapnya seperti pada gambar dibawah ini.

\section{KESIMPULAN}

Aspek bimbingan, konsultasi dan pendampingan manajemen usaha merupakan kegiatan yang sangat penting untuk perkembangan dan kemajuan bisnis. Pelaksanaan pendampingan manajemen usaha yang meliputi : manajemen keuangan,manajemen pemasaran,manajemen produksi dan manajemen sumberdaya manusia secara kontinyu dan berkesinambungan akan memberikan manfaat yang nyata untuk mencapai tujuan perusahaan yaitu laba dan kesejahteraan pemilik yang maksimal.

\section{DAFTAR PUSTAKA}

BPS, Bangkalan Dalam Angka 2015.

Departemen Perdagangan Republik Indonesia. 2008, Pengembangan Ekonomi Kreatif Indonesia 2025: Rencana Pengembangan Ekonomi Kreatif Indonesia 2009-2015.

James C. Van Horne, John M. Wachowicz, Jr..2005.Prinsip-prinsip Manajemen Keuangan, Buku 1 Edisi 12 (Soft Cover, Kertas HVS),Salemba Empat,Jakarta

Mathis, Robert L.2006.Human Resource Management : Manajemen Sumber Daya Manusia.Salemba Empat,. Jakarta

Philip Kotler. Kevin Lane Keller.2002. Manajemen Pemasaran (Jilid 1) (Edisi 13), Penerbit Erlangga, Jakarta

Rakhmat Makmur.2016. Bisnis Online. Penerbit Informatika. Jakarta 


\section{Jurnal Pangabdhi}

Sutarman, Pengantar Tehnologi Informasi, 2009.Penerbit Bumi Aksara, Jakarta

T.Hani Handok.2010.Dasar-Dasar Manajemen Produksi dan Operasi.Edisi 1. BPFE Yogyakarta 